Supporting Information

\section{Transition Path Sampling Study of the Feruloyl Esterase Mechanism}

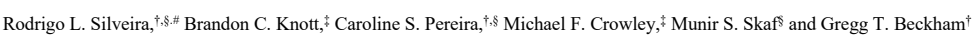
'Renewable Resources and Enabling Sciences Center and `Biosciences Center, National Renewable Energy Laboratory, Golden, Colorado 80401, United States

snstitute of Chem

"Institute of Chemistry, Federal University of Rio de Janeiro, Rio de Janeiro, RJ 21941-909, Brazil
Table S1. Candidate CVs for the first step.

$\mathrm{RC} 1=2.129-4.114 \mathrm{q} 7$

CC2 $=0.134+2.313 \mathrm{q}_{3}-2.558$

年

\begin{tabular}{|c|c|c|}
\hline Index & Type & Description \\
\hline $\mathrm{CV} 1$ & distance & Ser133(OG), FA(CF9) \\
\hline $\mathrm{CV} 2$ & distance & $\mathrm{FA}(\mathrm{CF} 9), \mathrm{Ara}(\mathrm{O} 5)$ \\
\hline CV3 & distance & $\mathrm{CV} 2-\mathrm{CV} 1$ \\
\hline $\mathrm{CV} 4$ & distance & Ser133(HG1), His247(NE2) \\
\hline CV5 & distance & Ser133(HG1), Ser133(OG) \\
\hline CV6 & distance & $\mathrm{CV} 4-\mathrm{CV} 5$ \\
\hline CV7 & distance & Ser133(HG1), Ara(O5) \\
\hline CV8 & distance & $\mathrm{CV} 7-\mathrm{CV} 4$ \\
\hline CV9 & distance & His247(NE2), Ara(O5) \\
\hline CV10 & distance & Ser133(OG), His247(NE2) \\
\hline CV11 & distance & $\mathrm{CV} 9-\mathrm{CV} 10$ \\
\hline CV12 & distance & Ser133(HG1), FA(CF9) \\
\hline CV13 & distance & Ser133(OG), Asp194(OD2) \\
\hline CV14 & distance & Ser133(OG), Ara(O5) \\
\hline CV15 & distance & His247(HD1), Asp194(OD2) \\
\hline CV16 & distance & His247(HD1), His247(ND1) \\
\hline CV17 & distance & CV15-CV16 \\
\hline CV18 & distance & Ara(O5), Asp194(OD2) \\
\hline CV19 & distance & Asp194(OD2), Glc22(NE2) \\
\hline CV20 & distance & Asp194(OD2), Ala257(N) \\
\hline CV21 & distance & His247(CA), Ser133(OG) \\
\hline CV22 & angle & Ser133(OG), Ser133(HG1), His247(NE2) \\
\hline $\mathrm{CV} 23$ & angle & His247(NE2), Ser133(HG1), Ara(O5) \\
\hline CV24 & angle & Ser133(OG), Ser133(HG1), Ara(O5) \\
\hline CV25 & angle & Ser133(OG), His247(NE2), Ara(O5) \\
\hline $\mathrm{CV} 26$ & angle & FA(CF9), Ser133(OG), His247(NE2) \\
\hline CV27 & angle & Ser133(OG), FA(CF9), Ara(O5) \\
\hline $\mathrm{CV} 28$ & angle & Ser133(OG), FA(CF9), FA(OF1) \\
\hline CV29 & angle & $\mathrm{Ara}(\mathrm{O} 5), \mathrm{FA}(\mathrm{CF} 9), \mathrm{FA}(\mathrm{OF} 1)$ \\
\hline $\mathrm{CV} 30$ & & $\operatorname{Ara}(\mathrm{O} 5), \mathrm{FA}(\mathrm{CF} 9), \mathrm{FA}(\mathrm{CF} 8)$ \\
\hline CV31 & dihedral & His247(CG), His247(CB), His247(CA), His247(C) \\
\hline CV32 & dihedral & $\operatorname{Ara}(\mathrm{O} 5), \operatorname{Ara}(\mathrm{C} 5), \mathrm{Ara}(\mathrm{C} 4), \operatorname{Ara}(\mathrm{O} 4)$ \\
\hline CV33 & dihedral & $\mathrm{FA}(\mathrm{OF} 1), \mathrm{FA}(\mathrm{CF} 9), \mathrm{FA}(\mathrm{CF} 8), \mathrm{FA}(\mathrm{CF} 7)$ \\
\hline CV34 & dihedral & $\mathrm{FA}(\mathrm{CF} 9), \mathrm{FA}(\mathrm{CF} 8), \mathrm{FA}(\mathrm{CF} 7), \mathrm{FA}(\mathrm{CF} 1)$ \\
\hline CV35 & dihedral & His247(CA), His247(CB), His $247(\mathrm{CG})$, His247(ND1 \\
\hline CV36 & dihedral & His 132(CA), His 132(CB), His132(CG), His132(ND) \\
\hline CV37 & improper & Ser133(OG), FA(CF9)*, $\mathrm{Ara}(\mathrm{O} 5), \mathrm{FA}(\mathrm{OF} 1)$ \\
\hline
\end{tabular}




\section{Table S2. Candidate CVs for the second step.}

$\mathrm{RC} 1=1.962-3.372 \mathrm{q} 7$

\begin{tabular}{|c|c|c|}
\hline Index & Type & Description \\
\hline $\mathrm{CV} 1$ & distance & Ser133(OG), FA(CF9) \\
\hline $\mathrm{CV} 2$ & distance & $\mathrm{FA}(\mathrm{CF} 9)$, Wat $(\mathrm{O})$ \\
\hline $\mathrm{CV} 3$ & distance & $\mathrm{CV} 2-\mathrm{CV} 1$ \\
\hline $\mathrm{CV} 4$ & distance & His247(NE2), Wat(H1) \\
\hline CV5 & distance & His247(NE2), Wat(H2) \\
\hline CV6 & distance & Ser133(OG), Wat(H1) \\
\hline CV7 & distance & Ser133(OG), Wat (H2) \\
\hline CV8 & distance & CV7-CV5 \\
\hline $\mathrm{CV} 9$ & distance & $\mathrm{CV} 6-\mathrm{CV} 4$ \\
\hline $\mathrm{CV} 10$ & distance & His247(NE2), Ser133(OG) \\
\hline CV11 & distance & His247(NE2), Wat(O) \\
\hline $\mathrm{CV} 12$ & distance & $\mathrm{CV} 11-\mathrm{CV} 10$ \\
\hline $\mathrm{CV} 13$ & distance & Wat(HI), FA(CF9) \\
\hline CV14 & distance & Wat(H2), FA(CF9) \\
\hline CV15 & distance & Ser133(OG), Asp194(OD2) \\
\hline CV16 & distance & Ser133(OG), Wat(O) \\
\hline CV17 & distance & His247(HD1), Asp194(OD2) \\
\hline CV18 & distance & His247(HD1), His247(ND1) \\
\hline CV19 & distance & CV17-CV18 \\
\hline CV20 & distance & Wat(O), Asp194(OD2) \\
\hline CV21 & distance & Asp194(OD2), Glc22(NE2) \\
\hline CV22 & distance & Asp194(OD2), Ala257(N) \\
\hline CV23 & distance & His $247(\mathrm{CA})$, Ser133(OG) \\
\hline CV24 & distance & Wat(H1), $\mathrm{FA}(\mathrm{OF} 1)$ \\
\hline CV25 & distance & Wat(H2), FA(OF1) \\
\hline CV26 & distance & $\mathrm{CV} 24-\mathrm{CV} 4$ \\
\hline CV27 & distance & CV $25-\mathrm{CV} 5$ \\
\hline CV28 & distance & Wat( $(\mathrm{O})$, Wat $(\mathrm{H} 1)$ \\
\hline CV29 & distance & Wat $(\mathrm{O})$, Wat $(\mathrm{H} 2)$ \\
\hline CV30 & distance & $\mathrm{CV} 28-\mathrm{CV} 4$ \\
\hline CV31 & distance & CV29-CV5 \\
\hline CV32 & distance & Wat(O), His247(NE2) \\
\hline CV33 & angle & Ser133(OG), Wat(H1), His247(NE2) \\
\hline CV34 & angle & Ser133(OG), Wat(H2), His247(NE2) \\
\hline CV35 & angle & His247(NE2), Wat(H1), Wat(O) \\
\hline CV36 & angle & His247(NE2), Wat(H2), Wat(O) \\
\hline CV37 & angle & Ser133(OG), Wat(H1), Wat(O) \\
\hline CV38 & angle & $\operatorname{Ser} 133(\mathrm{OG})$, Wat $(\mathrm{H} 2)$, Wat $(\mathrm{O})$ \\
\hline CV39 & angle & Ser133(OG), His247(NE2), Wat(O) \\
\hline CV40 & angle & FA(CF9), Ser133(OG), His247(NE2) \\
\hline CV41 & angle & Ser133(OG), FA(CF9), Wat(O) \\
\hline $\mathrm{CV} 42$ & angle & Ser133(OG), FA(CF9), $\mathrm{FA}(\mathrm{OF} 1)$ \\
\hline $\mathrm{CV} 43$ & angle & $\mathrm{Wat}(\mathrm{O})$, FA(CF9), FA(OF1) \\
\hline CV44 & angle & Wat(O), FA(CF9), FA(CF8) \\
\hline CV45 & angle & FA(OF1), Wat(H1), Wat(O) \\
\hline $\mathrm{CV} 46$ & angle & FA(OF1), Wat(H2), Wat(O) \\
\hline CV47 & angle & FA(CF9), FA(OF1), Leu134(HN) \\
\hline CV48 & angle & FA(CF9), FA(OF1), Thr68(HN) \\
\hline
\end{tabular}

\begin{tabular}{|c|c|c|}
\hline 749 & angle & FA(OF1), Wat(H1), Wat(O) \\
\hline CV50 & angle & $\mathrm{FA}(\mathrm{OF} 1)$, Wat(H2), Wat(O) \\
\hline CV51 & angle & Ser133(OG), FA(OF1), Thr68(N) \\
\hline CV52 & angle & $\operatorname{Wat}(\mathrm{H} 1)$, Wat $(\mathrm{O})$, Wat $(\mathrm{H} 2)$ \\
\hline CV53 & angle & Wat(H1), Wat((O), FA(CF9) \\
\hline CV54 & angle & Wat(H2), Wat(O), FA(CF9) \\
\hline CV55 & angle & Ser133(CB), Ser133(OG), FA(CF9) \\
\hline CV56 & dihedral & His247(CG), His247(CB), His247(CA), His247(C) \\
\hline CV57 & dihedral & $\mathrm{FA}(\mathrm{OF} 1), \mathrm{FA}(\mathrm{CF} 9), \mathrm{FA}(\mathrm{CF} 8), \mathrm{FA}(\mathrm{CF} 7)$ \\
\hline CV58 & dihedral & $\mathrm{FA}(\mathrm{CF9}), \mathrm{FA}(\mathrm{CF} 8), \mathrm{FA}(\mathrm{CF} 7), \mathrm{FA}(\mathrm{CF} 1)$ \\
\hline CV59 & dihedral & His247(CA), His247(CB), His247(CG), His247(ND1) \\
\hline $\mathrm{CV} 60$ & dihedral & His132(CA), His132(CB), His132(CG), His132(ND1) \\
\hline CV61 & dihedral & Ser133(OG), FA(CF9), FA(OF1), Leu134(HN) \\
\hline CV62 & dihedral & FA(OF1), FA(CF9), Ser133(OG), Ser133(CB) \\
\hline CV63 & dihedral & FA(OF1), FA(CF9), Wat(O), Wat(H1) \\
\hline $\mathrm{CV}_{64}$ & dihedral & $\mathrm{FA}(\mathrm{OF} 1), \mathrm{FA}(\mathrm{CF} 9), \mathrm{Wat}(\mathrm{O}), \mathrm{Wat}(\mathrm{H} 2)$ \\
\hline $\mathrm{CV} 65$ & dihedral & His247(NE2), Wat(H1), Watt(O), Wat(H2) \\
\hline CV66 & dihedral & His247(NE2), Wat(H2), Watt(O), Wat(H1) \\
\hline CV67 & improper & Ser133(OG), FA(CF9)*, Wat(O), FA(OF1) \\
\hline $\mathrm{CV}_{68}$ & improper & Leu134(HN), FA(OF1)*, Thr68(HN), FA(CF9) \\
\hline
\end{tabular}



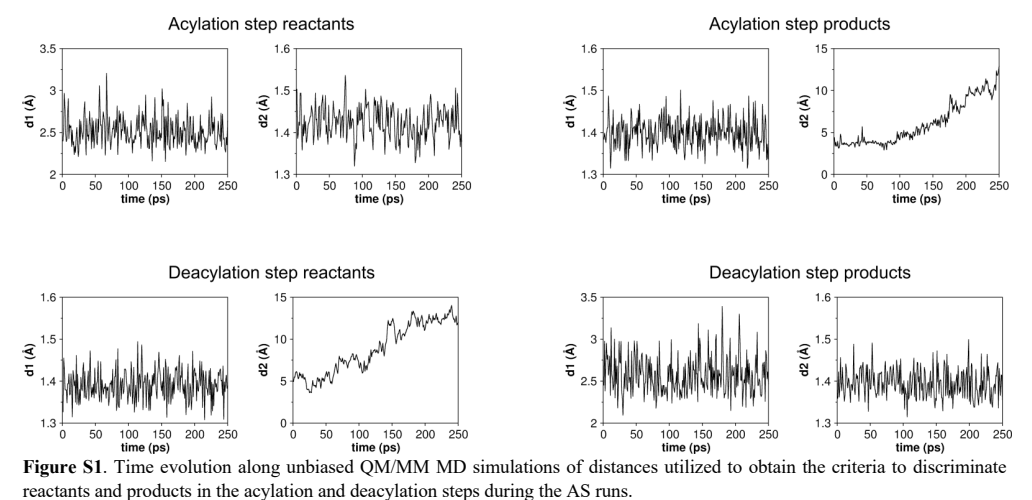

Figure S1. Time evolution along unbiased QM/MM MD simulations of distances
reactants and products in the acylation and deacylation steps during the $\mathrm{AS}$ runs.

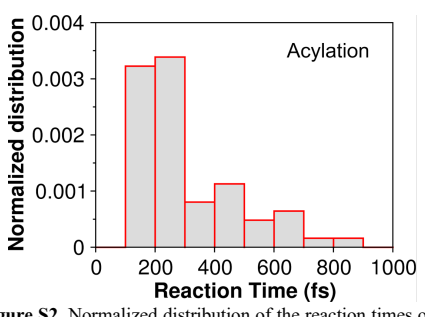

Figure S2. Normalized distribution of the reaction times of each reactive trajectory of the acylation (left) and deacylation (right)
step.

Ss

So 


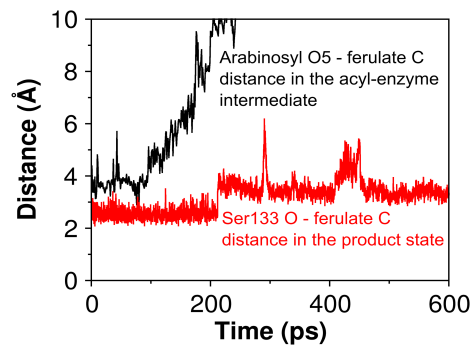

Figure S3. Distances representing the behaviours of the acylation and deacylation products (arabinose and ferulic acid respectively) during unbiased QMMMM simulations of the acyl-enzyme intermediate and product states. The black curve show that arabinose dissociates from the reactive center in about $150 \mathrm{ps}$. The red curve shows that, while ferulic acid is more tightly
bound to the enzyme than arabinosyl, it readily deviates from the conformation assumed right affer the end of the reaction indicating that the ferulic acid product would dissociate in a not much longer time scale. A classical MD simulation of the $A n$ FaeA-ferulic acid complex shows that the product dissociates in about 5 ns (data not shown).
A) Acylation step

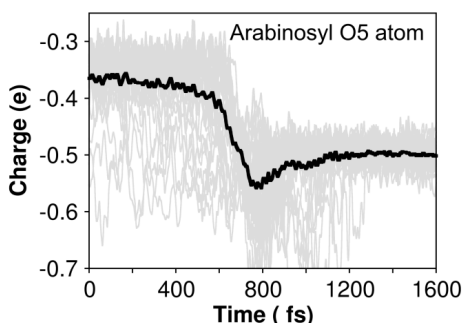

B) Deacylation step

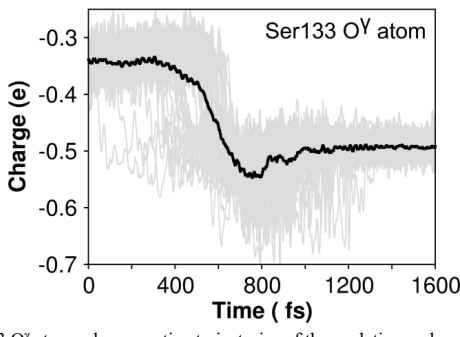

O5 and (B) Ser133 $\mathrm{O}^{\mathrm{y}}$ atoms along reactive trajectories of the acylation and deacylation steps, respectively. The black curves correspond to an average over the charges along individual aimless shooting trajectories, represented in grey. 


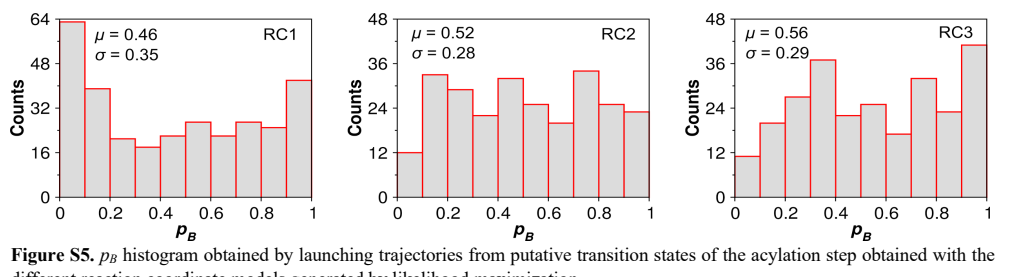

Figure S5. $p_{B}$ histogram obtained by launching trajectories from putative transition states of the acylation step obtained with the
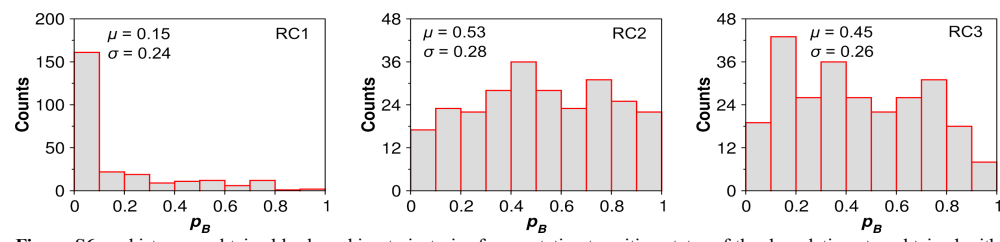
Figure $\mathbf{S 6}$. $p_{B}$ histogram obtained by launching trajectories from putative transi
the different reaction coordinate models generated by likelihood maximization. 


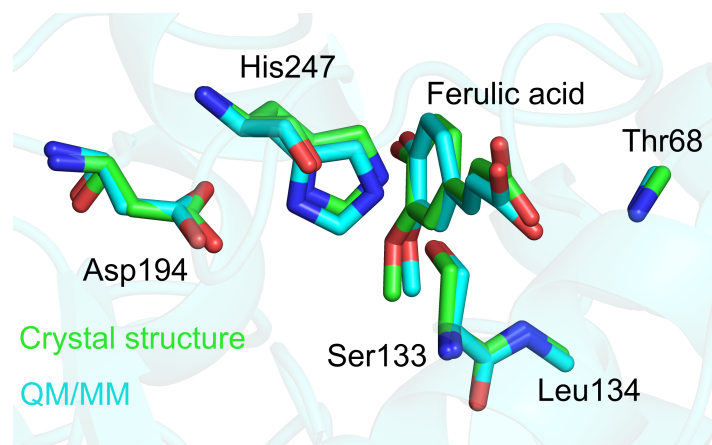

Figure S7. Structural comparison of the product configuration obtained with our QM/MM simulations (cyan) and the crystal

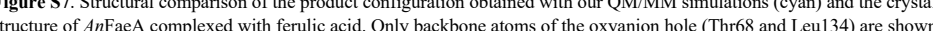
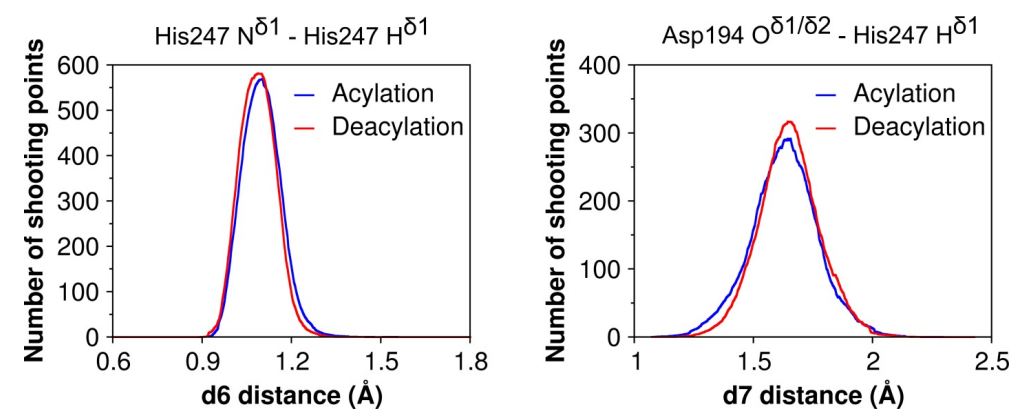

Figure S8. Distribution of the d 6 and d distances in all the 25,000 shooting points from which the Aimless Shooting trajectories are launched, showing that the His $247 \mathrm{H}^{\text {si }}$ proton is not effectively transferred to Asp 194 around the transition states. 